\title{
TECNOLOGIAS DIGITAIS E ARQUITETURAS PEDAGÓGICAS NA EDUCAÇÃO
}

\author{
Patricia Jantsch Fiuza ${ }^{1}$ \\ Roberta Ribas Mocelin ${ }^{2}$
}

\section{INTRODUÇÃO}

Este trabalho apresenta 0 andamento da pesquisa também intitulada "Tecnologias Digitais e Arquiteturas Pedagógicas na Educação" desenvolvido juntamente com o Grupo de Pesquisa em Mídia e Conhecimento (GPM\&C) e o Laboratório de Mídia e Conhecimento (Labmídia) da Universidade Federal de Santa Catarina (UFSC). As investigações deste estudo estão sendo aplicadas na região da Associação dos Municípios do Extremo Sul Catarinense (AMESC), tendo como alvo gestores, professores e alunos de escolas que possuem recursos tecnológicos à sua disposição. O principal objetivo deste trabalho é apresentar as etapas já concluídas e o que está em curso na pesquisa, listando as primeiras conclusões e contribuições alcançadas e as que ainda estão em processo.

Não é novidade a importância que as tecnologias digitais têm exercido no cotidiano do homem moderno. Nos últimos anos, especialmente, depara-se com um avanço muito significativo destas tecnologias, a ponto de transformar as formas de relacionamento. A praticidade destes dispositivos é tamanha, que hoje se podem pagar contas, fazer compras, "reunir-se" com pessoas, e uma infinidade de tarefas somente através deles, sem sequer sair de casa.

Dados divulgados pelo IBGE, levantados em 2013 através da Pesquisa Nacional por Amostra de Domicílio (Pnad), indicaram que, naquele ano, mais de $50 \%$ dos brasileiros acessam a internet através de celulares ou tablets. Engana-se quem pensa que este fato não atinge também a vida das crianças e jovens. Como dito anteriormente, a tecnologia evoluiu de maneira a transformar a forma como se relaciona com o mundo, e isso já é suficiente para alterar consideravelmente o perfil da criança e do jovem atual.

Essas mudanças trazem reflexos nos processos de aprendizagem, uma vez que o aprendiz também mudou seu comportamento. Por mais inovações tecnológicas que se tenham, elas ainda não chegaram às salas de aula. Nas escolas, ainda se vive no século passado, ainda se usam os mesmos métodos de 
ensino. Não que tais métodos sejam ruins, eles apenas estão, de certa forma, em desacordo com as inovações tecnológicas atuais, deixando de serem eficientes e ou interessantes perante o novo perfil do aluno.

Tendo em mente essas considerações, fica evidente a importância do tema deste trabalho, que objetiva investigar como a tecnologia pode contribuir nos processos de aprendizagem. Este é o primeiro passo a se tomar para construir uma base de conhecimento, tornando possível desenvolver mecanismos para a integração das tecnologias nos métodos de ensino, e suprir as necessidades pedagógicas encontradas.

\section{METODOLOGIA}

Este pesquisa constitui-se em uma pesquisa exploratória mista destinada a investigação da realidade das práticas docentes em relação à introdução de Tecnologias da Informação e Comunicação (TIC) como ferramentas de ensino. Portanto, o passo inicial foi a averiguação de como outros estudos têm retratado esta iniciativa, buscando compreender o que já está documentado sobre esta temática. Para este fim, foi escolhida a metodologia de Revisão Sistemática da Literatura (RSL), o que deu origem ao primeiro estudo que aponta como resultado inicial desta pesquisa, o estado da arte das tecnologias digitais e arquiteturas pedagógicas na educação. Após análises dos resultados encontrados na referida RSL, foi possível um panorama em como este assunto tem sido abordado até então. O próximo passo se configura na atuação em escolas, com o objetivo de entender quais as dificuldades e necessidades de gestores, docentes e discentes para com 0 uso das TIC na rotina escolar através de entrevistas e questionários. O resultado desta apuração busca revelar as adversidades em relação ao uso dos aparatos tecnológicos em sala de aula e como estes podem se configurar em um novo mecanismo no processo de aprendizagem. Depois de concluída esta etapa, será desenvolvida uma estratégia de atuação juntamente com gestores e docentes para contornar os problemas constatados e promover o uso das ferramentas tecnológicas disponíveis na escola. Esta atuação poderá ser na forma de oficinas, minicursos, workshops ou treinamento, o próprio processo delineará o melhor procedimento. 


\section{RESULTADOS E DISCUSSÃO}

Atualmente identifica-se o momento que se vive como "Sociedade da Informação", devido à grande importância que a internet e os dispositivos aliados a ela tomaram no cotidiano. Assim, é compreensível que haja uma demanda de inovação nos modelos de ensino. Nas últimas décadas alguns esforços governamentais foram executados, na esperança de incitar a inclusão digital dos alunos, bem como atualizar as metodologias de ensino. No entanto, a maioria destas iniciativas não obteve muito sucesso, principalmente pela falta de preparo de professores e gestores da educação. (TAJRA, 2008). Com os últimos avanços tecnológicos e principalmente com o aumento do uso da internet, as possibilidades de inclusão de TICs no ensino cresceram, muito embora no Brasil ainda não passem somente de possibilidades.

Com o intuito de compreender como a temática de Tecnologias da Informação juntamente com as Arquiteturas Pedagógicas tem sido retratada mundo a fora, foi realizado um estudo utilizando a metodologia de Revisão Sistemática de Literatura (RSL). Esta metodologia consiste em encontrar estudos relacionados a este tema, através de um sistema de buscas por palavras chaves e sistemas de filtragem em um banco de dados, possibilitando a obtenção do que mais se encaixa no perfil montado pelo pesquisador. Por fim, chega-se a um determinado número de estudos, dos quais se pode avaliar mais a fundo para construir a base de conhecimento necessária sobre o assunto (FREIRE, 2013). No fim deste processo, produziu-se o primeiro resultado da pesquisa "Tecnologias Digitais e Arquiteturas Pedagógicas na Educação", um capítulo de livro descrevendo o que foi descoberto ao final da RSL.

\subsection{REVISÃO SISTEMÁTICA DA LITERATURA}

Como apontado anteriormente, esta metodologia consiste em um conjunto de passos, a fim de explorar um tema, e compreender como ele tem sido tratado a nível mundial. O primeiro passo foi a construção de uma pergunta de pesquisa, tendo esta a responsabilidade de nortear a pesquisa. A pergunta de pesquisa elaborada foi a seguinte: quais as origens e tendências das publicações 
científicas sobre como as tecnologias digitais e as arquiteturas pedagógicas têm contribuído no processo de aprendizagem?

A partir deste passo, iniciou-se a pesquisa na base de dados SCOPUS. Foram aplicados cinco filtros, conforme a tabela abaixo:

Tabela 1 - Filtros aplicados à pesquisa na base de dados SCOPUS

\begin{tabular}{|c|l|l|}
\hline Ordem & \multicolumn{1}{|c|}{ Filtro } & \multicolumn{1}{c|}{ Resultado } \\
\hline $1^{\circ}$ & Education AND Technolog & 117.513 artigos encontrados \\
\hline $2^{\circ}$ & Digital & 19.766 artigos encontrados \\
\hline $3^{\circ}$ & Pedagogical & 2.999 artigos encontrados \\
\hline $4^{\circ}$ & "Digital Technolog*" & 414 artigos encontrados \\
\hline $5^{\circ}$ & Pedagogical Architectures & 29 artigos encontrados \\
\hline
\end{tabular}

Fonte: Fiuza e Mocelin (2016)

Neste momento, foram escolhidos os primeiros critérios de inclusão e exclusão. Optou-se por excluir livros e capítulos de livros, mantendo apenas artigos e papers, reduzindo a 20, o montante de trabalhos retornados com a pesquisa.

Ao finalizar esta parte da revisão, foi possível tomar algumas conclusões importantes sobre o tema:

- O tema é recente, tendo sua primeira publicação datada em 2001, e seu ápice de publicações em 2005;

- Não há mais de um artigo por autor nesta área;

- Há contribuições de diversos países, sendo os EUA o que mais contribuiu com publicações;

- Este tema pode ser considerado multidisciplinar, uma vez que se encaixa em, pelo menos, 7 áreas de estudo de maneira interdisciplinar;

O próximo passo foi realizar a leitura de todos os resumos, com o intuito de compreender sobre o que tratava cada texto. Mais uma vez, alguns trabalhos foram excluídos, mantendo apenas cinco para leitura completa. Estes cinco foram escolhidos de acordo com a sua proposta, pois apresentavam exemplos práticos e sua adaptabilidade ao âmbito de pesquisa do presente trabalho.

O resultado das análises dos artigos da RSL apontou que ainda há uma carência de estudos nesta área, especialmente sobre escolas de ensino fundamental e básico. Também falta investigar quais as reais vantagens de adotar 
TIC nos processos de aprendizagem. No entanto, ficou claro que existem muitas maneiras de tornar o ensino mais interessante através da tecnologia, sendo necessário preparo especialmente dos professores para conduzir este novo método de ensino com eficiência. Espera-se que a quantidade de estudos voltados a esta temática aumente, visto que a procura pela atualização dos modelos de ensino, aliando a tecnologia no cotidiano escolar é uma tendência mundial.

O foco deste estudo é conseguir, em parceria com as escolas detentoras de material tecnológico da região da AMESC, melhorar a utilização do referido material ajudando os docentes a explorá-lo da melhor maneira e de acordo com os objetivos de cada aula. O resultado final aponta para a efetiva utilização das ferramentas tecnológicas disponíveis em prol do melhoramento da aprendizagem dos alunos.

\subsection{PARCERIA COM A ESCOLA}

Depois de realizar o levantamento teórico sobre o assunto que fundamenta este trabalho, iniciou-se contato com escolas da região da AMESC a fim de estabelecer uma parceria para realização de uma pesquisa e proposta de intervenção. O Instituto de Ensino Quintiliano, situado no município de São João do Sul demonstrou interesse, e foi o escolhido para o andamento da pesquisa. Esta é uma escola municipal, atendendo crianças no ensino fundamental, e também atendendo jovens e adultos com o programa EJA (Ensino para Jovens e Adultos). Nesta escola há uma boa estrutura tecnológica, tendo além do laboratório de informática, cerca de 20 tablets educacionais, fornecidos pelo FNDE (Fundo Nacional de Desenvolvimento), e lousas digitais disponíveis para uso nas aulas.

Os professores da escola declaram ter interesse em utilizar os tablets educacionais em suas aulas, porém não tem domínio sobre a ferramenta, ou não se sentem capacitados para usá-los pedagogicamente. Neste contexto, a parceria firmada com a escola tem por objetivo investigar quais as dificuldades em integrar o tablet educacional nas aulas, e propor uma intervenção, como um treinamento, oferecendo capacitação aos docentes para trabalharem com os tablets nas suas aulas, de maneira a colaborar com a aprendizagem dos alunos. 
A partir disto, o primeiro passo seguido foi conhecer a ferramenta tablet educacional. Foi feito um estudo prático sobre o aparelho, buscando conhecer o sistema operacional, as funcionalidades oferecidas e suas limitações. Constatou-se que o aparelho pode ser considerado um tanto ultrapassado quando comparado aos disponíveis no mercado, no entanto, ele corresponde as expectativas quanto sua capacidade de exercer atividades pedagógicas, sendo indicado para uso em sala de aula em diversas atividades e disciplinas. A gama de aplicativos e jogos disponíveis para uso neste aparelho é satisfatória.

Feito este estudo, e tendo em mente o funcionamento do tablet educacional, partiu-se para a segunda etapa: a elaboração e aplicação de um questionário, destinado aos docentes, com o intuito de compreender a sua visão do uso de tecnologia na educação, suas dificuldades quanto a integração destes dispositivos em suas aulas, e suas sugestões sobre o assunto. Os resultados deste questionário ainda não foram apurados, caracterizando esta etapa como em andamento.

A partir dos resultados do questionário será possível a elaboração da intervenção prevista na pesquisa tema deste artigo. Tal intervenção tem o objetivo de apresentar o tablet educacional e suas funcionalidades aos professores, bem como sugestões de uso pedagógico. A intenção é preparar o docente para lidar com esta tecnologia, e ser capaz de pôr em prática atividades que contribuam no processo de aprendizagem de seus alunos, promovendo também inclusão digital, e aproveitando educacionalmente um recurso até então conhecido apenas por fins de entretenimento.

\section{CONCLUSÃO}

As atividades da pesquisa "Tecnologias Digitais e Arquiteturas Pedagógicas na Educação" ainda estão em andamento, recentemente entrando na parte prática que consiste na parceria com escolas. A conclusão da primeira etapa, a fundamentação teórica encontrada na produção do artigo nos moldes de RSL, foi de grande importância para consolidar a base desta pesquisa, reforçando a necessidade desta intervenção nas escolas, com o objetivo de aprimorar as metodologias de ensino através da aplicação de TICs nas aulas. Os resultados 
preliminares na parte prática realizada até o momento se mostram promissores, com a consolidação de uma parceria com uma escola modelo em um município pequeno que tem contribuído com conhecimentos importantes para o sucesso da intervenção e, consequentemente, da pesquisa.

Ressalta-se a importância dessas ações realizadas em parceria da UFSC e do Labmídia com as redes de ensino públicas da AMESC, buscando o benefício da comunidade escolar. Espera-se que ao final deste estudo os resultados possam contribuir com políticas públicas e ser replicados em mais escolas da região.

\section{REFERÊNCIAS}

FIUZA, Patricia e MOCELIN, Roberta Ribas. Systematic Review of Literature: The Contributions to the Learning Process by Digital Technologies and Pedagogical Architectures. In: ROCHA, Alvaro; et. al. (Org.). Advances in Intelligent Systems and Computing. 1ed. Switzerland: Springer International Publishing, 2016, v. 2, p. 225-234.

FREIRE, Patrícia de Sá. Aumente a qualidade e a quantidade de suas publicações científicas. Manual para elaboração de projetos e artigos científicos. Curitiba, PR: CRV, 2013.

TAJRA, Sanmya Feitosa. Informática na Educação: novas ferramentas pedagógicas para o professor na atualidade. 8 ed. rev. e ampl. São Paulo: Érica, 2008.

\section{Fontes Financiadoras:}

CNPQ através da concessão de Bolsa PIBIC. 